\title{
DOMINÓ DAS HORTALIÇAS: DESENVOLVIMENTO DE JOGO DIDÁTICO PARA HORTA ESCOLAR
}

\author{
Daniel Felipe Oliveira Gentil ${ }^{1}$ \\ Haroldo Silva Rodrigues ${ }^{2}$ \\ Reina Auxiliadora Gonçalves de Souza ${ }^{3}$
}

\begin{abstract}
Resumo
Esse artigo analisa o jogo como um recurso que pode promover a aprendizagem significativa no ambiente escolar, com objetivo de apresentar os procedimentos de desenvolvimento de jogo de dominó de hortaliças para ser aplicado em hortas escolares. O trabalho abrangeu as seguintes etapas: criação, determinação das regras e confecção do dominó das hortaliças folhosas e das hortaliças-fruto. O dominó das hortaliças, ao ser jogado, despertou interesse e prendeu a atenção das crianças. As regras sugeridas funcionaram adequadamente. $O$ material confeccionado proporcionou leveza, simplicidade, praticidade e beleza às peças. $\mathrm{O}$ jogo está pronto para ser disponibilizado às crianças participantes de hortas escolares.
\end{abstract}

Palavras-chave: dominó didático, material pedagógico, educação infantil.

\section{DOMINO OF VEGETABLES: DEVELOPMENT OF DIDACTIC GAME FOR SCHOOL GARDEN}

\begin{abstract}
The game is a resource that can promote learning in the school. The aim of this paper was relating the procedures for developing the game of domino of vegetables to be applied in school gardens. The work included the following steps: creation, determination of rules and preparation of domino leafy vegetables and fruiting vegetables. The domino of vegetables aroused interest and caught the attention of children. The suggested rules functioned properly. The material with which it was made, resulted in lightness, simplicity, practicality and beauty to parts. The game is ready to be made available to children participating of school gardens.
\end{abstract}

Key words: didactic domino, pedagogical material, child education.

\footnotetext{
${ }^{1}$ Professor Adiunto da Universidade Federal do Amazonas (UFAM). Doutorado em Agronomia (USP). E-mail: dfgentil@ufam.edu.br

${ }^{2}$ Graduação em Agronomia (UFAM). Mestrando em Genética e Melhoramento (UFV). E-mail: roldoagro@hotmail.com

${ }^{3}$ Graduação em Agronomia (UFAM). Graduação em Serviço Social (UFAM). E-mail: reinasouza@bol.com.br
} 


\section{INTRODUÇÃO}

No ambiente escolar, a abordagem lúdica pode facilitar a aprendizagem em processos de socialização, expressão e construção do conhecimento, bem como colaborar para o desenvolvimento físico, mental, emocional e social dos envolvidos (S ANTOS e CRUZ, 1997; MALUF, 2003), além de influenciar nos hábitos alimentares. Por isso, muitas escolas já estão promovendo, cada vez mais, brincadeiras, brinquedos e jogos em salas de aula (MALUF, 2003).

Independentemente da época, cultura e classe social, os brinquedos e jogos fazem parte da vida das crianças, pois elas vivem em um mundo de fantasias, encantamentos, alegrias e sonhos, onde realidade e faz-de-conta se confundem (SANTOS e CRUZ, 1997). É brincando e pensando sobre o brincar que se adquire consciência sobre a sua importância (KISHIMOTO, 2001). O jogo possui implicações importantíssimas em todas as etapas da vida psicológica infantil e representa erro inaceitável considerá-lo trivial ou perda de tempo (ANTUNES, 2003).

No contexto atual da educação infantil, segundo Kishimoto (2001), a ação de brincar pode ter significações distintas: educadores que valorizam a socialização adotam o brincar livre; e, educadores que visam à escolarização ou aquisição de conteúdos escolares, em que o brincar e os jogos educativos são dirigidos.

Para Kishimoto (2003), o jogo educativo aparece com dois sentidos: a) sentido amplo: como material ou situação que permite a livre exploração em recintos organizados pelo educador, visando o desenvolvimento geral da criança; e b) sentido restrito: como material ou situação que exige ações orientadas com vistas à aquisição ou treino de conteúdos específicos de habilidades intelectuais. Nesse segundo caso, recebe também o nome de jogo didático. Embora a distinção entre os dois tipos de jogos esteja presente na prática usual dos educadores, pode-se dizer que todo jogo é educativo em sua essência, pois em qualquer tipo de jogo a criança sempre se educa (KISHIMOTO, 2003).

Quanto mais recursos o educador disponibilizar para a aprendizagem e para o desenvolvimento infantil, mais meios terá para alcançar os objetivos funcionais de sua disciplina e, de maneira simétrica, as finalidades educacionais (SENA e LIMA, 2009). O jogo é um recurso didático que, ao mesmo tempo, pode ensinar, aprimorar as relações interpessoais e, ainda, causar intensa sensação de alegria, prazer e motivação (ANTUNES, 2003).

O interesse do aluno passou a ser a força que comanda o processo de aprendizagem e o educador um gerador de instruções estimuladoras e eficazes (ANTUNES, 1998). Para Sena e Lima (2009), compete ao educador atuar como mediador e enxergar o potencial de aprendizagem e de desenvolvimento que se escondem por trás das situações e atitudes lúdicas que o jogo promove. É nesse contexto que o jogo ganha importância, como ferramenta ideal de aprendizagem, na medida em que propõe estímulo ao interesse do aluno. Constitui instrumento pedagógico que leva o educador a condição de condutor, estimulador e avaliador da aprendizagem (ANTUNES, 1998). Os jogos infantis podem até excepcionalmente incluir uma ou outra competição, mas visam estimular o crescimento e a aprendizagem, e representam relação interpessoal entre dois ou mais sujeitos, realizada dentro de determinadas regras (ANTUNES, 2003). Não significa desqualificar o espírito competitivo, muito menos negar a sua existência no jogo, pois não é a competição boa ou ruim por natureza, mas sim o modo como os indivíduos, organizados ou não, se apropriam dessa manifestação e fazem uso dela (RETONDAR, 2007).

A novidade dos jogos de regras é o seu caráter coletivo, pois neles as ações devem ser reguladas por convenções que definem o que os jogadores podem ou não fazer, 
implicando na condução do processo educativo da criança, a aprender a disciplinar o seu próprio comportamento. Assim, tanto as regras quanto as estratégias do jogo são aprendidas pelas crianças nas interações com os colegas, durante o jogo.

Os jogos de regras envolvem regularidades e o prazer funcional da repetição. Como recurso da aprendizagem, a repetição está na base da formação de hábitos, que é fundamental para a educação escolar (SANTOS e ALVES, 2000).

Em pesquisa realizada por Kishimoto (2001), com professores de escolas de educação infantil, foi verificado que, entre os brinquedos/materiais educativos que favorecem o lúdico, o dominó foi considerado importante. Em sua forma mais conhecida, conforme Santos e Alves (2000), o dominó envolve regras simples e alguns conceitos que são ensinados na pré-escola: a correspondência entre cores, formas e quantidades. Pode-se preparar, continuando os autores, diferentes tipos de dominó, de modo que, sendo jogados com as mesmas regras, apresentem dificuldades conceituais crescentes. Dessa maneira, o próprio jogo pode servir como contexto-suporte para novas aquisições de conhecimento.

Um único jogo pode em determinadas circunstâncias, proporcionar elemento de intenso prazer na criança, mas sua aprendizagem somente se concretizará quando este jogo tiver correspondência com um projeto de conhecimento, com etapas claramente estabelecidas (ANTUNES, 2000). Portanto, ao fazer uso do jogo como recurso pedagógico, o educador deve organizar o ambiente educativo, a fim de instigar, motivar e conduzir esse recurso como uma atividade promotora de aprendizagem e, por conseguinte, de desenvolvimento cognitivo e pessoal (SENA e LIMA, 2009).

O Projeto "Horta Escolar" é uma ação vinculada ao Programa Atividade Curricular de Extensão (PACE) da Pró Reitoria de Extensão e Interiorização (PROEXTI) da Universidade Federal do Amazonas (UFAM). Está em andamento, desde sua implantação no $2^{\circ}$ semestre de 2006, na Escola Estadual Brigadeiro João Camarão Telles Ribeiro, em Manaus, Amazonas, visando ensinar sobre o cultivo de hortaliças aos alunos da Escola e proporcionar um campo de experiência profissional, em horta educativa no ensino fundamental, aos estudantes do Curso de Agronomia da UFAM. Até o presente, o número de alunos participantes da Escola foi em torno de 25 por semestre, enquanto o de estudantes do Curso de Agronomia foi, em média, de nove por semestre (GENTIL e SOUZA, 20.11).

As atividades de campo, na "Horta Escolar", não são realizadas em dias chuvosos e nos horários mais quentes do dia (entre 10:00 e 15:00 horas). Nessas ocasiões, o tempo é usado para o diálogo como os alunos sobre algum tema relacionado à implantação e manutenção de hortas (GENTIL e SOUZA, 2011). Desse modo, surgiu a necessidade do desenvolvimento de instrumentos que facilitassem o processo educativo, como um jogo para estimular as inteligências pictórica e naturalista dos alunos (ANTUNES, 1998), através da habilidade do reconhecimento de hortaliças.

Assim, o objetivo deste trabalho foi apresentar os procedimentos de desenvolvimento de jogo de dominó de hortaliças para ser usado em hortas escolares.

\section{MÉTODOS}

O trabalho foi realizado no Setor de Olericultura da Faculdade de Ciências Agrárias da UFAM, em Manaus, Amazonas, entre 2010 e 2012. Abrangeu três etapas sequenciais, a saber:

- Criação do dominó das hortaliças. Inicialmente, foram ilustradas as hortaliças mais cultivadas no Estado do Amazonas e a logomarca do Projeto "Horta Escolar", através do programa de design gráfico CorelDRAW. Em seguida, na definição das espécies e 
do número de espécies para a composição do dominó, foi adotada a análise combinatória cujo número de combinações com repetições de $n$ elementos tomados $p$ a $p$ foi dada por $C_{(n+p-1, n-1)}=(n+p-1) ! / p !(n-1)$ ! (CDCC - USP, 2012).

- Determinação das regras do dominó das hortaliças. A partir das regras do jogo de dominó comum, foram adaptadas regras mais simples e adequadas ao processo educativo.

- Confecção do dominó das hortaliças. Em ensaio-piloto, foram testados a manufatura e o jogar do dominó.

\section{RESULTADOS E DISCUSSÕES}

$\mathrm{Na}$ criação do dominó, além da logomarca do Projeto "Horta Escolar", as hortaliças ilustradas foram as seguintes: alface (Lactuca sativa), alfavaca (Ocimum micranthum), berinjela (Solanum melongena), cariru (Talinum triangulare), cebolinha (Allium schoenoprasum), chicória (Eryngium foetidum), coentro (Coriandrum sativum), couve (Brassica oleracea var. acephala), feijão-de-metro (Vigna unguiculata subsp. sesquipedalis), jambu (Acmela oleracea), jerimum (Cucurbita moschata), maxixe (Cucumis anguria), melancia (Citrullus lanatus), pepino (Cucumis sativus), pimentade-cheiro (Capsicum frutescens), pimentão (Capsicum annuum), quiabo (Abelmoschus esculentus), repolho (Brassica oleracea var. capitata) e tomate (Lycopersicon esculentum).

Em jogos de dominó, cada peça retangular é dividida ao meio, sendo que cada lado apresenta uma ilustração (CUNHA, 2010). Ao aplicar a análise combinatória, para a verificação do número de combinações com repetições, sendo $n=20$ (ilustrações) e $p$ = 2 (duas a duas, na mesma peça de dominó), foi obtido o resultado de 210 combinações ou peças de dominó. Então, considerando o número elevado de peças, optou-se pela divisão do dominó em dois jogos: o das hortaliças folhosas (alface, alfavaca, cariru, cebolinha, chicória, coentro, couve, jambu e repolho, além da logomarca "Horta Escolar") e o das hortaliças-fruto (berinjela, feijão-de-metro, jerimum, maxixe, melancia, pepino, pimenta-de-cheiro, pimentão, quiabo e tomate, além da logomarca "Horta Escolar"). Mas, ainda assim, o número de peças continuou elevado, com 55 e 66 combinações, respectivamente. Diante disso, apesar de mantida a formação de dois jogos, foi decidido seguir o mesmo número de combinações do dominó comum, que é de 28 peças (CUNHA, 2010), com $n=7$ (ilustrações) e $p=2$ (duas a duas, na mesma peça de dominó). Isso resultou em dois jogos de hortaliças (Figura 1), a saber: o das hortaliças folhosas (alface, cebolinha, coentro, couve, jambu e repolho, além da logomarca "Horta Escolar") e o das hortaliças-fruto (jerimum, maxixe, pepino, pimentão, quiabo e tomate, além da logomarca "Horta Escolar"). 


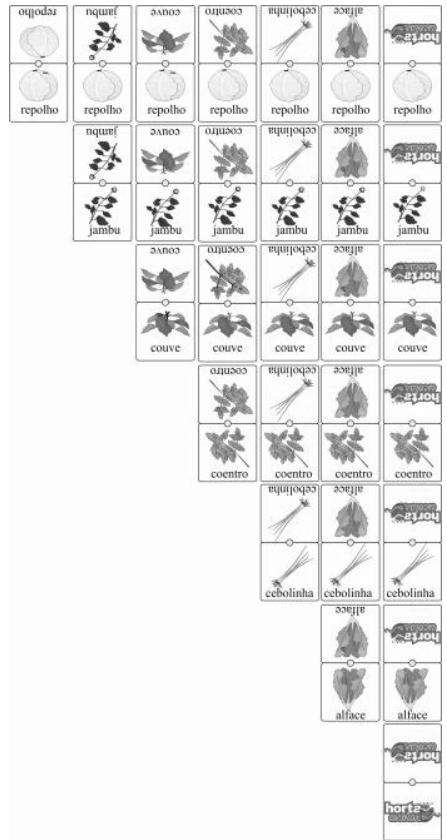

(a)

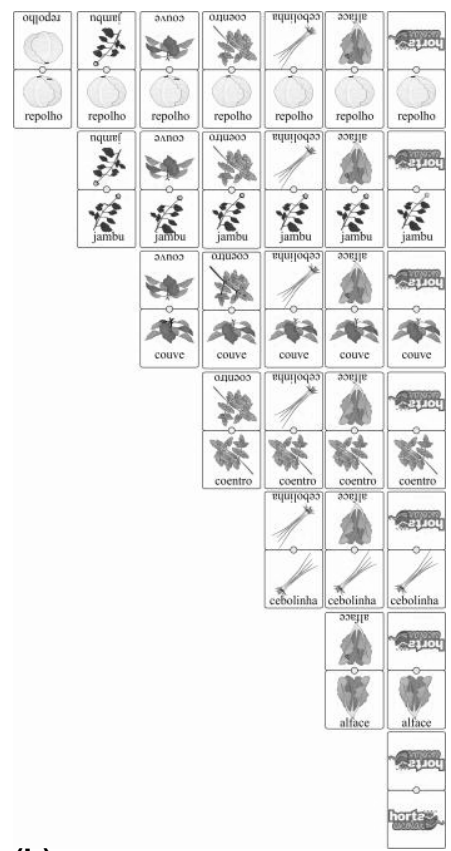

(b)

Figura 1 - Dominó das hortaliças folhosas (a) e das hortaliças-fruto (b) para aplicação em hortas escolares. Manaus, UFAM, 2012.

O jogo de dominó é um dos brinquedos sugeridos para crianças do período intuitivo (4 a 7 anos) e do período das operações concretas (7 a 12 anos), por Cunha (2010). Segundo Antunes (1998), os jogos devem ser utilizados somente quando a programação educativa possibilitar e se constituírem em auxílio eficiente ao alcance dos objetivos dentro dessa programação. De certa forma, a elaboração da programação deve ser precedida do conhecimento de jogos específicos para poder incluí-los, sempre com senso crítico para mantê-los, alterá-los ou substituí-los por outros, se for percebido que ficaram distantes dos objetivos propostos (Antunes, 1998).

O dominó das hortaliças poderá ser jogado seguindo as seguintes regras:

- O dominó será jogado por quatro crianças;

- Inicialmente, as peças serão embaralhadas, com as ilustrações voltadas para baixo, e distribuídas às crianças, que ficarão com sete peças cada uma;

- O jogo começará pela criança que possuir a peça "Horta Escolar". Esta peça será a única a possibilitar a ramificação do jogo nas quatro direções;

- As outras crianças, sequencialmente a partir da esquerda daquela que iniciou, deverão agrupar uma meia-peça correspondente a alguma terminação das peças nas ramificações sobre a mesa. Caso não tenha nenhuma peça correspondente, a criança deixará de jogar na rodada e a vez passará para a criança seguinte;

- A criança que colocar a última peça, ganhará o jogo.

A existência de regras é uma característica marcante em todos os jogos (Kishimoto, 2003). As regras representam os limites dentro dos quais as crianças podem brincar, muito embora sejam flexíveis para que aprendam e explorem livremente aqueles aspectos mais interessantes do jogo (PROCTOR e NIMNITCH, 1984). Nesse sentido, as 
regras dos jogos podem ser mudadas tantas vezes quanto necessário, oportunizando a criação e recriação de seu universo lúdico (RETONDAR 2007).

No contexto educacional, conforme Sena e Lima (2009), o emprego do jogo pode ser enriquecido e potencializado pela qualidade e frequência das intervenções do educador. É preciso que os educadores se coloquem como participantes, acompanhando todo o processo da atividade, mediando os conhecimentos através do jogo (MALUF, 2003). Entretanto, a voluntariedade é elemento presente e fundamental. Não há jogo sem vontade de jogar ou vontade de continuar jogando. A voluntariedade remete ao principio da autonomia e coloca o sujeito como responsável por suas decisões e atos (RETONDAR, 2007).

O jogo de dominó das hortaliças foi impresso colorido em papel A4. Em seguida, cada folha foi colada sobre chapa de papelão reciclado e cada figura, correspondente a cada peça, foi recortada com o auxílio de estilete. Ao final, cada peça apresentou 97 $\mathrm{mm}$ de comprimento, $50 \mathrm{~mm}$ de largura e $3 \mathrm{~mm}$ de espessura.

Segundo Cunha (2010), a embalagem é parte importante do brinquedo, não somente para sua conservação, mas também para sua funcionalidade, estimulando o hábito de guardar o jogo após o uso. Assim, pode ser sugerido que as peças dos dominós das hortaliças sejam guardadas separadamente, conforme o grupo ao qual pertencem folhosas ou frutos (Figura 1), presas por liga de borracha e acondicionadas em sacos de pano com cordão de amarração.

Após sua confecção, o dominó das hortaliças passou a ser usado como recurso didático na "Horta Escolar". Essa foi uma ação orientada aos alunos do projeto para contribuir na aprendizagem sobre o cultivo de hortaliças, fora do horário ou na impossibilidade das atividades de campo. Paralelamente, oficinas de confecção do dominó, acompanhadas de palestras sobre a importância das hortaliças na alimentação humana, foram realizadas com alunos não vinculados ao projeto, visando estimular neles o consumo de hortaliças. Portanto, este jogo didático está sendo empregado conforme o surgimento das oportunidades para o aprendizado, como um dos meios para se alcançar as finalidades pedagógicas do projeto.

\section{CONSIDERAÇÕES FINAIS}

O dominó das hortaliças, ao ser jogado, despertou interesse e prendeu a atenção das crianças. As regras sugeridas funcionaram adequadamente. O material, com o qual o mesmo foi confeccionado, proporcionou leveza, simplicidade, praticidade e beleza às peças. O jogo está pronto para ser disponibilizado às crianças participantes de hortas escolares.

No processo educativo, a abordagem lúdica também representa um modo de repasse de conteúdos específicos. Neste sentido, a utilização do dominó das hortaliças se mostrou viável como jogo didático em horta escolar. Mas, é necessário que os educadores o utilizem em contexto adequado à aprendizagem e associado a um projeto de conhecimento. Este pode envolver temas variados relacionados às hortaliças ilustradas, como: valor nutricional, usos, origem, propagação, cultivo, dentre outros. Afinal, se o educador não atuar como mediador, as crianças brincarão com o dominó como se fosse outro qualquer e logo perderão o interesse neste jogo didático. 


\section{AGRADECIMENTOS}

Os autores agradecem à PROEXTI/UFAM e à Escola Estadual Brigadeiro João Camarão Telles Ribeiro, pela viabilização do Projeto "Horta Escolar".

\section{REFERENCIAS BIBLIOGRÁFICAS}

ANTUNES, C. Jogos para a estimulação das múltiplas inteligências. 8.ed. Petrópolis: Vozes, 1998. 295p.

ANTUNES, C. $\mathbf{O}$ jogo e a educação infantil: falar e dizer, olhar e ver, escutar e ouvir. f.15. Petrópolis: Vozes, 2003. 86p.

CDCC - USP. Análise combinatória e probabilidade: orientação para o professor. CDCC - USP, Experimentoteca, 11p. (Matemática, 8). Disponível em: http://www.cdcc.usp.br/exper/medio/matematica/

matematica_medio/8_permutação_arranjo_pdf. Acesso em: 5 maio 2012.

CUNHA, N.H.S. Brinquedoteca: um mergulho no brincar. 4.ed. São Paulo: Aquariana, 2010. 126p.

GENTIL, D.F.O.; SOUZA, R.A.G. Horta Escolar: um espaço didático-pedagógico. Horticultura Brasileira, v.29, n.2, 2011 (Suplemento - CD ROM).

KISHIMOTO, T.M. Brinquedos e materiais pedagógicos nas escolas infantis. Educação e Pesquisa, v.27, n.2, p.229-245, 2001.

KISHIMOTO, T.M. O jogo e a educação infantil. São Paulo: Pioneira Thomson Learning, 2003. 62p.

MALUF, A.C.M. Brincar: prazer e aprendizado. 3.ed. Petrópolis. Vozes, 2003. 111p.

PROCTOR, M.; NIMNICHT, G. Jogos que educam: instruções para o uso de brinquedos pedagógicos. Brasília: MPAS/SAS, 1984. 76p.

RETONDAR, J.J.M. Teoria do jogo: a dimensão lúdica da existência humana. Petrópolis: Vozes, 2007. 95p.

SANTOS, J.G.W.; ALVES, J.M. O jogo de dominó como contexto interativo para a construção de conhecimentos por pré-escolares. Psicologia: Reflexão e Crítica, v.13, n.3, p.383-390, 2000.

SANTOS, S.M.P.; CRUZ, D.R.M. O lúdico na formação do educador. In: SANTOS, S.M.P. O lúdico na formação do educador. 6.ed. Petrópolis: Vozes, p.11-17,1997.

SENA, S.; LIMA, J.M. O jogo como precursor de valores no contexto escolar. Revista Brasileira de Educação Física e Esporte, v.23, n.3, p.247-262, 2009. 